\title{
The application of workflow control in colonoscopy department
}

\author{
Hsueh-Ling Ku ${ }^{1}$, Chia-Long Lee ${ }^{2}$, Ya-Hui Chen ${ }^{3}$, Yu-Hui Chiu ${ }^{4,5}$ \\ ${ }^{1}$ Department of Endoscopy, ${ }^{2}$ Department of Internal Medicine, ${ }^{3}$ Department of Medical Research, Cathay General Hospital, Taipei, Taiwan; \\ ${ }^{4}$ Department of Emergency Medicine, Mackay Memorial Hospital, Taipei, Taiwan; ${ }^{5}$ Department of Emergency, School of Medicine, College of \\ Medicine, Taipei, Taiwan \\ Contributions: (I) Conception and design: HL Ku, CL Lee; (II) Administrative support: CL Lee; (III) Provision of study materials or patients: HL Ku; \\ (IV) Collection and assembly of data: HL Ku, YH Chiu; (V) Data analysis and interpretation: YH Chen; (VI) Manuscript writing: All authors; (VII) \\ Final approval of manuscript: All authors. \\ Correspondence to: Dr. Yu-Hui Chiu. Department of Emergency Medicine, Mackay Memorial Hospital, 92, Section 2, Zhongshan North Road, Taipei \\ 10449, Taiwan. Email: yuhui7786@gmail.com.
}

Background: Health and longevity are pursued by many people. Colonoscopy examination is the most effective method for the early diagnosis of colorectal cancer. The use of painless colonoscopy can further increase patient safety, comfort, and satisfaction. Therefore, the "Examination Workflow Management" is an important index for achieving both patient safety and medical care quality.

Methods: This research is of a prospective design that utilized observation, measurement, and analysis of "Examination Workflow Management" to improve the presented issues. A total of 145 patients were compared between before and after intervention periods. The interventions included examining instrument resources, allocating team staff, and inspecting scheduling procedure.

Results: The direct observations included checking daily procedures, patient waiting duration, examination time, patient satisfaction, overall procedural duration, first examination delayed start time, room turnover time, total examined patient numbers and daily nurse overtime. The indirect observations included patient scheduling and appointment, scheduled patient cancellation rate, and staff satisfaction.

Conclusions: "Examination Workflow Management", the standard of medical center operating room, was utilized to achieve the goal, including allocating equipment resources and team staff members, reviewing patient scheduling, and evaluating patient satisfaction and unit efficiency. The 18 month-long continual observation, intervention, and correction indeed improved the quality of painless colonoscopy medical service in our medical institution.

Keywords: Examination workflow management; painless colonoscopy examination; patient satisfaction; quality improvement; unit efficiency

Received: 15 November 2019; Accepted: 19 May 2020; Published: 19 June 2020.

doi: 10.21037/ht-19-27

View this article at: http://dx.doi.org/10.21037/ht-19-27

\section{Introduction}

Colonoscopy can be utilized for the early screening and treatment of colorectal cancer. Colorectal cancer is the second most common diagnosed cancer in the United States, where 50,000 people will die from colorectal cancer each year. The American Cancer Society recommends that starting at age 50, men and women should receive colonoscopy every 10 years. The prevalence and mortality rate of colorectal cancer has been rapidly increasing in Taiwan, where it has become the third leading cause of cancer death. According to the cancer registry statistics, the prevalence of colorectal cancer has increased 97\%, from 4,217 [standardized to 22.9 per 1 million population (PMP)] to 12,000 (standardized to 45.1 PMP) from 1995 to 2006, respectively, where it has exceeded the prevalence of hepatic carcinoma. The mortality rate has also increased from 2,469 (13.3 PMP) to 5,265 (15.3 PMP) from 1995 to 2013, 
respectively. Currently, the Taiwan Ministry of Health and Welfare, Health Promotion Administration has begun to advocate the prevention of colorectal cancer as well as subsidizing colorectal screening services (1).

The painless colonoscopy medical service investigated in this study is a non-invasive outpatient endoscopic procedure with general anesthesia. It is currently the most effective and safe methods for the early detection and treatment of colorectal diseases. The procedures for painless colonoscopy are performed with the use of general anesthesia, while the patient is unconscious and painless. The most important topic for patients undergoing painless colonoscopy examination is proper control of the examination workflow. Medical care service is a workflow management that provides a series of resources such as materials, labor, technology, profession, knowledge, information, facilities, time, and space to the customers. Stringent data collection and statistical analysis were used to identify and eliminate the source of the issues. Internal procedural management such as high quality control stability and low deviation can ensure the smooth execution of the routine procedure for satisfying the expectation and needs of the patient and increasing institution efficiency.

The management of endoscopy examination workflow is a medical team service procedure management that included personnel, operation, materials, and equipment management. The quality and efficiency of the management can be determined from indicating factors such as examination day waiting time, case satisfaction, case overall procedural duration, delay for the first procedure of the day, room turnover time, daily number of examined patients, daily nurse overtime, patient satisfaction, and staff satisfaction (2). In order to satisfy the patient expectations and fulfil medical institution accreditation endoscope examination standards, all aspects (including personnel, operation, materials, and equipment) of the endoscopy examination room must be designed to provide patient safety, comfort, immediacy, and staff satisfaction.

Therefore, we flexible utilized and scheduled of "Examination Workflow Management", the standard of medical center operating room, for achieving an effective, objective, and efficient examination; the examination must be precise and accurate; the equipment easy to operate and is in the optimal conditions; and the team members must receive related pre-employment, occupational training, and team oriented cooperative training. In addition, all equipment, instrument, and materials used during the endoscopy examination must undergo strict infection control for proving a quality and comprehensive care for the patients before, during, and after the examination $(3,4)$. Due to the advancement in medical technologies, diversification of medical care service models, and medical insurance policies, many of the traditionally inpatient procedures are slowly being transitioned to be performed in the outpatient service. Therefore, patient safety, comfort, immediacy, efficiency, and fairness, as well as the cost efficiency of the procedures, have become important topics for providing a quality outpatient medical care procedure. The painless (general anesthesia) endoscopy examination service room should be established according to the medical center operating room standards. The standards should include pre-, during, and post-examination patient requirements and expectations; environmental infection control such as clean and contaminated areas; strict inspection, cleaning, and high-level disinfection of instruments and endoscope; professional education and training, and allocation of all operation personnel (examination physician and anesthesiologist, endoscopy room and nurse anesthetist, and endoscopy technicians); unit personnel resource and material management (patient, staff, facility, and material process flow); the respect and safeguard of patient privacy; procedure scheduling management, and the establishment of all related standard operating procedures (5).

\section{Method}

\section{Hospital Information}

This research was performed in an endoscopy examination unit in the gastroenterology department in a 750-bed medical center in Northern Taiwan. The provided examination services include ultrasound and gastrointestinal endoscopy examinations. The gastrointestinal examination is available to all inpatients (11.3\%), outpatients (88.7\%), where it is also available for the regular (98.5\%) and emergency (1.5\%) department. A total of 7 rooms that are compatible with gastrointestinal examinations are located in area A (5 rooms) and area B (2 rooms). There were a total of 30 sets of fiber optic gastroscopy and colonoscopy instruments available. Each of the area has an independent infection compliant disinfection room and endoscopy cleaning and sterilization equipment. There were also two preparation rooms and 8 anesthesia recovery rooms in area $\mathrm{B}$. The care team consisted of 15 gastrointestinal examination physicians, 10 nurses, 


\begin{tabular}{|c|c|c|c|c|}
\hline $\begin{array}{l}\text { Intake } \\
\text { 1. Equipment } \\
\text { resources } \\
\text { inspection } \\
\text { 2. Operating } \\
\text { team staff } \\
\text { 3. Scheduling } \\
\text { review } \\
\text { 4. Procedure } \\
\text { review }\end{array}$ & 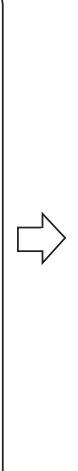 & $\begin{array}{l}\text { Transform } \\
\text { Workflow } \\
\text { management } \\
\text { inspection }\end{array}$ & 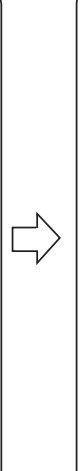 & $\begin{array}{l}\quad \text { Output } \\
\text { Direct indexes } \\
\text { 1. Patient waiting time } \\
\text { 2. Patient satisfaction } \\
\text { 3. Patient overall workflow duration } \\
\text { 4. First examination delay } \\
\text { 5. Room turnover rate } \\
\text { 6. Total number of examined patients } \\
\text { 7. Nurse overtime } \\
\text { Indirect indexes } \\
\text { 1. Patient schedule reservation time } \\
\text { 2. Patient cancelation rate } \\
\text { 3. Staff satisfaction }\end{array}$ \\
\hline
\end{tabular}

Figure 1 Research concepts.

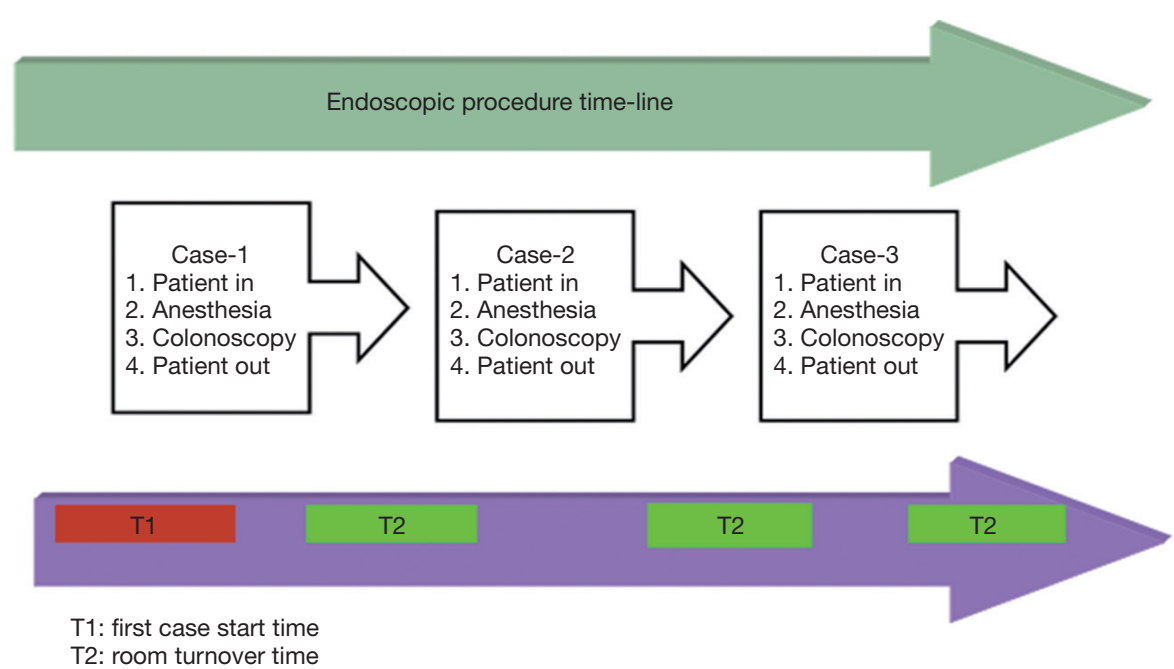

Figure 2 Painless colonoscopy examination procedure.

2 anesthesiologists, and 10 nurse anesthetist anesthesia nurses. Area A and B examination rooms are open 5.5 and 5 days per week, respectively. The daily working hours are 8 a.m. to 5 p.m. The annual ultrasound, gastroscopy, and endoscopy examinations were 24,000, 11,000 and 10,000 patients respectively, out of these patients, $80 \%$ of which were outpatients that have undergone painless (general anesthesia) procedures.

\section{Research concepts (shown in Figure 1)}

\section{Research detail}

(I) This research is of a prospective design.

(II) Painless colonoscopy examination room daily workflow: The examination room procedures are shown in Figure 2. The first examination start time is indicated as $\mathrm{T} 1$, where $\mathrm{T} 2$ is the room turnover time.

(III) Study duration: The pre-improvement period was defined as between Mar. $1^{\text {st }}$ to Mar. $31^{\text {st }}, 2015$. The post-improvement period was defined a between Sep. $1^{\text {st }}$ to Sep. $31^{\text {st }}, 2015$.

(IV) Scope: Observe and analyze all patients underwent examination in room 1 and room 2 in endoscope area B.

(V) Subjects: Cases that underwent painless endoscopy examinations, with pre- and post-intervention cases of 145 people each.

(VI) Intervention measures: With the goal "Examination Workflow Management", the following management measures were implemented.

i. The inspection and management of equipment 
resources: equipment such as the imaging system, flexible fiberscope, cleaning and sterilization equipment were rated at before, during, and after examination (level 1,2, and 3) for their state of cleanliness and maintenance for ensuring their proper functions.

ii. Staff management: The endoscopy examination room is comprised of a highly professional and integrated team. The staff must receive a series of pre-employment training, certified with The Digestive Endoscopy Society of Taiwan, for practitioner qualifications. The specialist must also obtain required education credits each year in order to maintain a valid license. Therefore, the patient examination procedure must be strictly followed and allocate different personnel for different patient care standard and examination requirements, yet, also maintain flexibilities for fulfilling goal of the examination unit for the achievement of a comprehensive team care.

iii. Examination scheduling management: The first examination is scheduled to commence at 8 a.m. each day. Ideally, three patients should be examined every hour. The patients are assigned to their respective examination rooms according to their schedules and room availability. All participating medical care personnel must not arrive late at the examination room to prevent delays. All work related procedures should follow as required for a functional care team.

iv. Examination procedure management: The examination room will only be used for patient examination. Each examination room will have a corresponding preparation room for the anesthesiologist and nurses to perform preexamination preparations for reported patients (verification of patient identity, examination procedural safety identification, time-out, intravenous catheter insertion, examination room arrangement, and patient safety checks) to reduce the patient preparation time after entering the examination room.

(VII) Evaluation metrics.

i. Direct observations: Including examination day examination procedures, patient waiting duration, examination time, patient satisfaction, overall procedural duration, first examination delayed start time, room turnover time, total examined patient numbers (room), and daily nurse overtime (person).

ii. Indirect observations: Including patient scheduling and appointment, scheduled patient cancellation rate, and staff satisfaction.

\section{Results}

\section{Direct observation evaluation details}

The average patient waiting time was significantly decreased from 28 to $21.7 \mathrm{mins}$, before and after improvements, respectively. The total examination workflow duration was significantly decreased from 50.2 to 47.5 mins, before and after improvements, respectively. The first examination delay was significantly reduced from 55.2 to 9.9 mins, before and after intervention, respectively. The room turnover time reduced from 11.4 to $5.3 \mathrm{mins}$, before and after intervention, respectively. The average patient satisfaction was significantly improved from $3.42 \pm 1.2$ to $4.62 \pm 0.8$, before and after intervention, respectively. The daily total examined patient was significantly improved from 17 to 24 patients, before and after intervention, respectively. The daily nurse overtime was significantly reduced from 128 to 30 mins, before and after intervention, respectively (Tables 1 and 2).

\section{Indirect observation evaluations}

The patient scheduling time was significantly improved by $54 \%$, where the average scheduled time before intervention (from March $1^{\text {st }}$ to March $31^{\text {st }}, 2014$ ) was 19 days and the average schedule time after intervention was (from Sep $1^{\text {st }}$ to Sep $30^{\text {th }}, 2015$ ) 8.7 days. The patient cancelation rate was significantly improved by $94 \%$, with before and after intervention cancelation rates of $3.5 \%$ and $0.2 \%$, respectively. The average staff satisfaction before intervention was $3.56 \pm 1.5$, where it was significantly improved to $4.52 \pm 1.1$ after intervention.

\section{Discussion}

This care utilized the integration and allocation of medical care team members for the improvement of medical care procedures. Issues such as unsuitable medical equipment and facilities resource arrangements, inappropriate allocation of human resource, and improper examination scheduling management can be solved by the utilization of 
Table 1 Comparison before and after intervention (patient related)

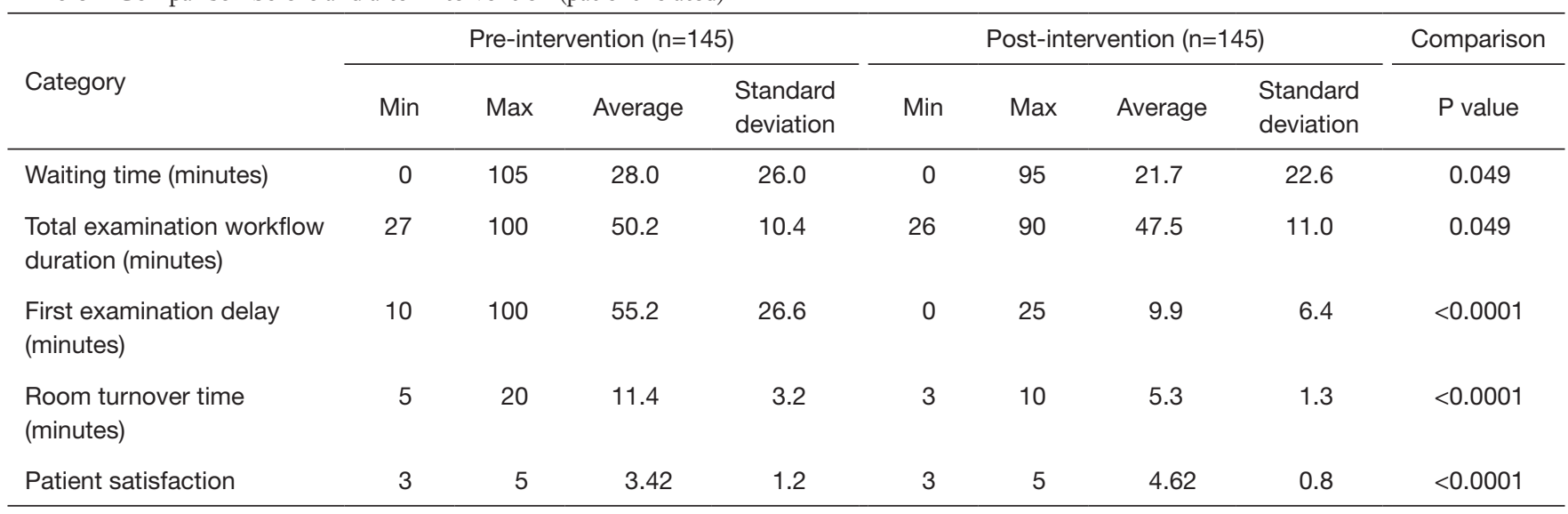

Table 2 Pre- and Post-improvement comparison (examination unit related)

\begin{tabular}{lccc}
\hline Category & Pre-intervention & Post-intervention & Improvement \\
\hline Average daily total patient number (room) & 17 & 24 & $+29 \%$ \\
Average daily nurse overtime (person) & 128 & 30 & $-77 \%$
\end{tabular}

quality improvement measures. These measures can include identifying issues, identifying causes, establishing goals, implementing intervention measure, evaluating results, and performing continual follow-ups (6). This study determined that the colonoscopy examination room was identified with issues such as improper examination workflow, extended examination scheduling wait time, extended patient examination wait time, and too much staff overtime hours. Therefore, direct and indirect observations were utilized for observing, measuring, and analyzing patient waiting time, total examination workflow duration, first examination delayed start time, number of daily examined patient, daily nurse overtime, and patient satisfactions; and patient scheduling time, patient cancelation rate, and staff satisfaction, respectively, for determining the effect of our improvement measures. The intervention measures were based on the "Examination Workflow Management", such as managing all examination instrument resources, care team staff, and inspecting scheduling procedure. An 18 month-long continual observation, intervention, and correction were performed to achieve the optimal direct and indirect observation goals.

In the recent pursuit of health for the citizens and the promotion of healthy lifestyles among worldwide nations, with the recent issues of unsafe cooking oil in Taiwan, many people have started to pay special attention to the prevention, diagnosis, and treatment of colorectal cancer. Therefore, receiving regular colonoscopy examination is the most effective and simple method for early detection. The establishment of a safe, comfortable, and efficient examination environment for patient safety is the goal of all medical institutions. The concepts and management model utilized in this study for endoscopy examination room management is exactly the same as that of an operating room management (5). This study also demonstrated that endoscopy management philosophy and environment design is completely concurrent to that of an operating room. This philosophy treats the endoscopy examination room as an independent units, where the examination room personnel (patients and staff management), operation (examination scheduling and workflow management), materials (imaging, cleaning, and high-level sterilization instruments), infection control planning; which included personnel (patient and medical staff) and materials routing, should be exactly the same as operating room requirements for achieving a safe, comfortable, immediate, fair, and efficient examination environment for the patients.

The examination room management is a comprehensive management since each sector's function is deeply related to the operation of one another. Therefore, this study utilizes "Examination Workflow Management" as the main process for ensuring the success of each management measures. 
In terms of examination instrument resources, these resources can be categorized into imaging system, flexible fiberscope, cleaning and sterilization equipment were rated at before, during, and after examination (level 1 , 2 , and 3) for their state of cleanliness and maintenance for ensuring their proper functions. Ensuring the proper function of all valuable medical resources and imaging system for the use of examiner can achieve the safe, accurate, and timely examination of patients. Furthermore, the repeated disinfection of flexible fiberscope should be strictly performed as per infection control standard operating procedure to eliminate the possible patient cross-contamination and ensure the effectiveness of the equipment. This procedure is in accordance to pastdemonstrated literatures (7-10).

In terms of medical team management, the endoscopy examination room is comprised of a highly professional and integrated team as mentioned above. At the workplace, all cooperating staff must performed their task and procedures with the patients in mind for simplifying, communication, inspecting, and eliminating all inefficient time during examination operation for an effective team cooperation. All participating medical care personnel must not arrive late at the examination room to prevent delays. All work related procedures should be followed for a cooperative, flexible, and functional care team to establish an efficient and friendly care model. The establishment of such medical care team is similar to those proposed by (11). It is the strict compliance to the examination procedure process and fulfilling the different care requirements to achieve unit targets for the development of a comprehensive team care model.

In terms of the management of examination workflow, the first examination is scheduled to commence at 8 a.m. each day. Ideally, three patients should be examined every hour. The patients are assigned to their respective examination rooms according to their schedules and room availability. All participating medical care personnel must not arrive late at the examination room to prevent delays. The colonoscopy examination preparation is very tedious. In order to achieve an unobstructed view of the patient's colon for the endoscopy specialists, each patient is required to undergo a 3-day colon cleanse. Therefore, when scheduling examination times, sufficient amount of time is required to allow the patient to be examined under their optimal conditions. The scheduling interval must be reasonable in order not to interfere with patient rights, increase patient waiting time, and increasing patient pre- examinations anxiety and discomfort. Therefore, allocating sufficient time for patient examination and maintaining adequate buffers are necessary (12).

The examination room will only be used for patient examination. Each examination room will have a corresponding preparation room for the anesthesiologist and nurses to perform pre-examination preparations for reported patients (verification of patient identity, examination procedural safety identification, timeout, intravenous catheter insertion, examination room arrangement, and patient safety checks) to reduce the patient preparation time after entering the examination room. Medical examination process inefficiencies will result in a longer waiting time for the patients. This study also determined that after reporting in, many patients are required to wait prior to receiving examination, indirectly, the scheduling of the examination also required many days of waiting. It was determined that these delays are caused by inefficient control of downtime in the examination workflow, including staff, operation, and policy issues, that resulted in the delay in the first examination start time and the extended room turnover rate. The improvement interventions were able to solve the issues of prolonged patient waiting and examination workflow time by eliminating personnel delays (patient and staff) and instrument malfunction and undersupply for the goals of on-time start of the first examination (reduce delay) and reduced room turnover rate to reduce examination downtime. This improvement strategy is concurrent to those proposals $(6,13-16)$. The implementation of quality assurance and improvement programme can lead to dramatic improvements in the quality of endoscopic care and patient outcomes (17).

In this study, we integrated examination room of material and human resources, established management and control for the achievement of excellent overall performance. After a period of operation, the continual review and improvement of the entire process resulted in daily increases in the number of examined patients, with 54\% reduction in the average scheduling and appointment time. At the same time, due to the integration model of cooperation between the care team staff, significant improvements were observed in job performance improvement, overtime reduction, and workplace satisfaction improvements.

\section{Conclusion}

This research demonstrated the process of establishing 
a patient centered quality examination environment. "Examination Workflow Management", the standard of medical center operating room, was utilized for inspecting unit inspection equipment resources, team staff members, inspecting patient scheduling. Patient satisfaction and unit efficiency were increased with the comprehensive analysis, integration, and management.

Due to the immeasurable worth and the limited quantity of time, the unnecessary waiting time and inefficient medical idling time is the cause of an unsafe medical environment. Therefore, the examination service workflow that is design with the patients in mind is very important. Furthermore, the interdisciplinary cooperation and integration of all involving medical team staff for the achievement and establishment of quality patient care environment is the goal of all medical care managers.

\section{Acknowledgments}

Funding: None.

\section{Footnote}

Data Sharing Statement: Available at http://dx.doi. org/10.21037/ht-19-27

Conflicts of Interest: All authors have completed the ICMJE uniform disclosure form (available at http://dx.doi. org/10.21037/ht-19-27). The authors have no conflicts of interest to declare.

Ethical Statement: The authors are accountable for all aspects of the work in ensuring that questions related to the accuracy or integrity of any part of the work are appropriately investigated and resolved. The study was conducted in accordance with the Declaration of Helsinki (as revised in 2013). The study was approved by the institutional review board of Cathay General Hospital (NO. CGH-P108125) and informed consent was taken from all individual participants.

Open Access Statement: This is an Open Access article distributed in accordance with the Creative Commons Attribution-NonCommercial-NoDerivs 4.0 International License (CC BY-NC-ND 4.0), which permits the noncommercial replication and distribution of the article with the strict proviso that no changes or edits are made and the original work is properly cited (including links to both the formal publication through the relevant DOI and the license). See: https://creativecommons.org/licenses/by-nc-nd/4.0/.

\section{References}

1. Austin H, Henley SJ, King J, et al. Changes in colorectal cancer incidence rates in young and older adults in the United States: what does it tell us about screening. Cancer Causes Control 2014;25:191-201.

2. Gellad ZF, Thompson CP, Taheri J. Endoscopy unit efficiency: quality redefined. Clin Gastroenterol Hepatol 2013;11:1046-1049.e1.

3. Beilenhoff U, Neumann CS. Quality assurance in endoscopy nursing. Best Pract Res Clin Gastroenterol 2011;25:371-85.

4. Stebbing JF. Quality assurance of endoscopy units. Best Pract Res Clin Gastroenterol 2011;25:361-70.

5. Deas T Jr, Sinsel L. Ensuring patient safety and optimizing efficiency during gastrointestinal endoscopy. AORN J 2014;99:396-406.

6. Peltokorpi A. How do strategic decisions and operative practices affect operating room productivity? Health Care Manag Sci 2011;14:370-82.

7. Association of periOperative Registered Nurses. Recommended practices for environmental cleaning in the surgical practice setting. AORN J 2002;76:1071-16.

8. Brogmus G, Leone W, Butler L, et al. Best practices in OR suite layout and equipment choices to reduce slips, trips, and falls. AORN J 2007;86:384-394; quiz 395-398.

9. ASGE Standards of practice committee, Banerjee $S$, Shen B, et al. Infection control during GI endoscopy. Gastrointest Endosc 2008;67:781-90.

10. Beilenhoff U, Neumann CS, Rey JF, et al. ESGEESGENA guideline: cleaning and disinfection in gastrointestinal endoscopy. Endoscopy 2008;40:939-57.

11. Butler V, Clinton C, Sagi HK, et al. Applying science and strategy to operating room workforce management. Nurs Econ 2012;30:275-81.

12. van Essen JT, Hurink JL, Hartholt W, et al. Decision support system for the operating room rescheduling problem. Health Care Manag Sci 2012;15:355-72.

13. Dexter F, Epstein RH, Marcon E, et al. Estimating the incidence of prolonged turnover times and delays by time of day. Anesthesiology 2005;102:1242-8; discussion 6A.

14. van Veen-Berkx E, Elkhuizen SG, Kalkman CJ, et al. Successful interventions to reduce first-case tardiness in Dutch university medical centers: results of a nationwide operating room benchmark study. Am J Surg 
2014;207:949-59.

15. Dexter EU, Dexter F, Masursky D, et al. Both bias and lack of knowledge influence organizational focus on first case of the day starts. Anesth Analg 2009;108:1257-61.

16. Bhatt AS, Carlson GW, Deckers PJ. Improving operating

doi: $10.21037 /$ ht-19-27

Cite this article as: $\mathrm{Ku} \mathrm{HL}$, Lee CL, Chen YH, Chiu YH. The application of workflow control in colonoscopy department. Health Technol 2020;4:3. room turnover time: a systems based approach. J Med Syst 2014;38:148.

17. Gado AS, Ebeid BA, Axon AT. Quality assurance in gastrointestinal endoscopy: An Egyptian experience. Arab J Gastroenterol 2016;17:153-8. 